\title{
Corrigendum: The influence of flexible work arrangements on employee engagement: An exploratory study
}

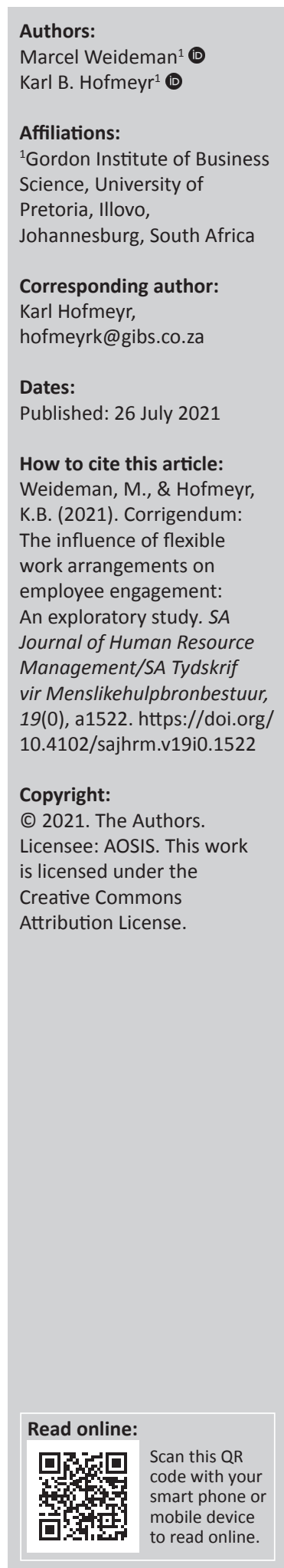

In the version of this article published earlier, Weideman, M., \& Hofmeyr, K.B. (2020). The influence of flexible work arrangements on employee engagement: An exploratory study. SA Journal of Human Resource Management/SA Tydskrif vir Menslikehulpbronbestuur, 18(0), a1209. https://doi.org/10.4102/sajhrm.v18i0.1209, the first author's affiliation was given incorrectly in the 'Authors' and 'Affiliations' sections. The correct affiliation should be 'Gordon Institute of Business Science, University of Pretoria, Illovo, Johannesburg, South Africa' instead of 'Independent, Johannesburg, South Africa'.

This correction does not alter the study's findings of significance or overall interpretation of the study results. The authors apologise for any inconvenience caused. 


\section{The influence of flexible work arrangements on employee engagement: An exploratory study}

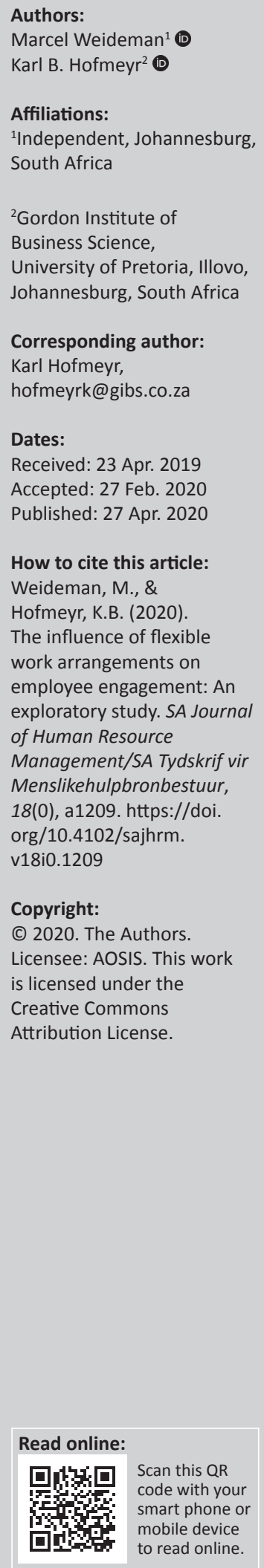

Orientation: The influence of flexible work arrangements (FWAs) on employee engagement.

Research purpose: This research was conducted to explore the influence of FWAs on employee engagement in order to gain a richer understanding than what is offered in pre-existing literature, and to provide practical recommendations to practitioners through a proposed framework.

Motivation for the study: Flexible work arrangements are becoming increasingly popular management practices within the business landscape. Significant research has been conducted to understand the influence of FWAs on various employee engagement constructs; however, these findings still show considerable variations and are highly inconsistent.

Research approach/design and method: This study used a qualitative mono method to explore the influence of FWAs on employee engagement. Qualitative, exploratory data allowed the researchers to gain new insights. A total of 23 semi-structured, face-to-face interviews were conducted. Respondents comprised eight subject matter experts and 15 employees from six different organisations, across six different industries. Interviews were analysed using a thematic analysis approach.

Main findings: This study found a positive relationship between FWAs and employee engagement. It also revealed that FWAs were positively associated with various employee engagement constructs found in the literature, with the most prominent finding showing positive influence of FWAs on employee well-being.

Practical/managerial implications: This study further developed a proposed framework for the successful implementation of FWAs to improve employee engagement.

Contribution/value-add: This study offers theoretical, methodological and practical implications for employee engagement and human resource development scholars and practitioners motivated to find ways to better manage FWAs and improve employee engagement.

Keywords: flexible work arrangements; employee engagement; employee well-being; selfmanagement; organisational culture.

\section{Introduction}

Flexible work arrangements (FWAs) are employment practices that allow workers flexibility in how they perform their tasks. The most common forms of FWAs include flexible working hours and working from home (Allen, Johnson, Kiburz, \& Shockley, 2013). The attention paid to FWAs has been fuelled by research that suggests positive correlations with employee engagement and job performance (Bal \& De Lange, 2014; Zeijen, Peeters, \& Hakanen, 2018).

The organisational costs associated with ignoring employees' personal commitments include high absenteeism and employee turnover (Kurtessis et al., 2017). In addition, FWAs have been highlighted as policies that can assist in maintaining a work-life balance, employee well-being and productivity (Caesens, Marique, Hanin, \& Stinglhamber, 2016). For organisations to improve their performance, further research into the influence of FWAs on employee engagement is necessary (Saks, 2006; Zhong, Wayne, \& Liden, 2015).

Employee engagement is defined as an employee's cognitive, behavioural and affective energy reflected in his or her work performance (Christian, Garza, \& Slaughter, 2011). Employee engagement has roused global interest of researchers and practitioners as organisations recognise the positive impact and competitive advantage that engaged employees bring to an organisation's performance 
(Kahn \& Heaphy, 2014). Employee engagement results in the enhancement of various performance outcomes for organisations, including financial considerations, productivity, customer satisfaction, a decrease in employee absenteeism and an increase in overall product or service quality (Bakker \& Demerouti, 2007).

A study undertaken by Towers Watson (2017) across 50 organisations globally reported a $19.2 \%$ increase in operational income amongst organisations that showed high employee engagement. The study also noted a $3.74 \%$ higher operating margin in organisations with a high employee engagement score. A similar meta-analysis study reported positive correlations between employee engagement and profitability, customer satisfaction, safety, decreased absenteeism and a decrease in defective products (Gallup, 2016).

\section{Research purpose and objectives}

Literature has suggested a relationship between FWAs and various constructs of employee engagement (Chen \& Fulmer, 2017). However, the number of variables that drive employee engagement is theoretically infinite. For organisations to improve their employee engagement and promote organisational performance and competitiveness, a better understanding of the contributing factors that influence employee engagement is needed (Kahn \& Heaphy, 2014). This research set out to explore the influence that FWAs have on employee engagement.

The objective of this research was to establish why organisations in South Africa implement FWAs, investigate the employee engagement benefits that organisations perceive upon implementing FWAs, understand the experiences of employees who make use of FWAs through an employee engagement lens, determine the drawbacks of FWAs and understand how FWAs can be improved to promote employee engagement.

\section{Literature review}

Flexible work arrangements have gained considerable interest from both researchers and practitioners; however, the benefits of implementing FWAs in organisations are still debated (Allen et al., 2013). Flexible work arrangements have been described as self-management practices that allow employees to control how they manage and allocate their resources in terms of time, attention and energy (Allen et al., 2013). The two most common examples of FWAs include flexitime, which allows employees to determine their work's start and finish times (Michel, Kotrba, Mitchelson, Clark, \& Baltes, 2011), and flexplace, which allows employees to work remotely (Allen et al., 2013).

Previous research has suggested that FWAs can impact various constructs that have been associated with employee engagement, such as organisational commitment (Bal \& De Lange, 2014). The organisational costs of ignoring personal commitments and responsibilities of employees include high absenteeism and turnover (Kurtessis et al., 2017). Gajendran and Harrison (2007) suggest that providing employees with FWAs will result in better talent retention as well as happier and more productive employees.

\section{Flexible work arrangements}

Flexibility is defined as the opportunity organisations provide to their employees regarding choice of where and when to work (Allen et al., 2013). Literature mentions about two types of flexibility within organisations. The first is referred to as irregular flexibility, which is a practice that allows employees to cope with an irregular amount of work over a given period (Casper \& Harris, 2008). The second is regular flexibility, which refers to daily flexibility whereby employees can choose their work schedules, start and finish times, and job-sharing arrangements (Bal \& De Lange, 2014). For the purpose of this study, regular flexibility will be used when referring to FWAs. Examples of FWAs include flexitime (employees are able to choose their start and end times), compressed work weeks (working longer days and fewer days per week) and telecommuting (use of technology to stay connected) (Michel et al., 2011).

Flexible work arrangements have gained significant interest amongst organisations globally. The World at Work Report (2015) reported that globally $80 \%$ of organisations offer employees some form of FWA. South African organisations and managers have been described as being conservative in terms of offering their employees the benefit of FWAs (IOL Business Report, 2017).

A common motive for organisations to implement a flexible work arrangement policy is to assist employees to better balance their time, where commuting times consumed a major portion of employees' time (Chen \& Fulmer, 2017). A global traffic survey, conducted by TomTom in 2016, revealed that travel time in South Africa is greatly affected by peak travel time congestion. An average of an additional 37 min per day's travel time, during peak traffic, was added to the commute (TomTom Traffic Index, 2016). A study conducted by Van Ommeren and Gutierrez-i-Puigarnau (2011) showed a direct correlation between commute times and absenteeism. A further study found a significant relationship between commuting and stress (Zhou et al., 2017). Both absenteeism and stress related to work-life conflict are constructs used to determine levels of employee engagement (Kurtessis et al., 2017).

A study by Thompson, Payne and Taylor (2015) revealed that younger generations entering the workplace generally favour having a greater choice over their work and non-work activities, being more inclined to blend the two at their own discretion, while the older generations prefer defined boundaries of work and non-work. Flexible work arrangements have become an expectation of younger generations within the workplace (Lyons \& Kuron, 2014). 
Sweet, Pitt-Catsouphes and Boone James (2016) discovered that older managers were less likely to implement FWAs and that women were more inclined to use and implement such arrangements.

\section{Employee engagement}

Kahn (1990) defines employee engagement as a work situation whereby employees are engaged cognitively, physically and emotionally in their job roles. Kahn (1990) further describes employee engagement as a state whereby employees find their work to be meaningful, to the extent where they choose to invest in their work with the objective of achieving personal and career growth. Engaged employees execute their work with passion and energy (Kahn \& Heaphy, 2014).

Employee engagement is broad in definition and theory (Christian et al., 2011). There are three different constructs of employee engagements that seem consistent in the literature, namely, cognitive engagement (an employee's focus on his or her work), emotional engagement (an employee's sense of purpose and belonging) and behavioural or physical engagement (the amount of effort an employee is willing to put into his or her work) (Shuck, Adelson, \& Reio, 2017; Zhong et al., 2015).

To effectively interpret qualitative responses through an employee engagement lens, it was important to identify the most common antecedents of employee engagement. The antecedents that were most pronounced in the literature, in no particular order, were as follows: (1) discretionary effort, (2) job satisfaction, (3) employee well-being, (4) trust in the organisation, (5) organisational commitment, (6) intention to turnover and (7) organisational support (Agarwal \& Gupta, 2018; Bailey, Madden, Alfes, \& Fletcher, 2017; Brunetto, Teo, Shacklock, \& Wharton, 2012; Rich, Lepine, \& Crawford, 2010; Saks, 2006; Shuck et al., 2017; Zhong et al., 2015).

\section{Flexible work arrangements and organisational commitment}

Chen and Fulmer (2017) found a positive relationship between FWAs and organisational commitment. Flexible scheduling and location, as opposed to working fewer hours, were found to be more positively associated with organisational commitment (Chen \& Fulmer, 2017). However, the study noted that there was no significant difference between organisational commitment levels in those employees who make use of FWAs and those who simply have the option of FWAs but make no use of them. The study concluded that an increase in organisational commitment is not purely a result of making use of FWAs, but that signalling and social exchange effects play a significant role in the increased organisational commitment outcome. There are, however, conflicting studies that portray FWAs in a negative light. These studies argue that FWAs may have unintended effects, such as an increase in worklife conflict and potential career penalties (Hammer, Neal,
Newsom, Brockwood, \& Colton, 2005; Leslie, Manchester, Park, \& Mehng, 2012).

\section{Flexible work arrangements and work-life balance}

Non-monetary policies such as FWAs have been found to be effective life-coping strategies compared to monetary-funded initiatives such as health and well-being programmes, children facilities and supportive services (Zheng, Kashi, Fan, Molineux, \& Ee, 2015).

Researchers argue that FWAs and managerial support and understanding enable employees to balance work with lifestyle and family commitments (Skinner \& Chapman, 2013). Flexible arrangements have been positively related to affective commitment and perceived organisational support and negatively related to intention to turnover (Casper \& Harris, 2008).

Work-life balance has also become increasingly popular amongst millennials (Lyons \& Kuron, 2014). The generation of millennials, first described by David Food as the 'Baby Boom Echo', was used to describe the generation born between 1980 and 1995 (Burke \& Ng, 2006). A review of the popular literature suggests that millennials tend to seek instant gratification in terms of good remuneration, career advancement, challenging work, societal contribution and a work-life balance. Millennials have reportedly seen their parents make immense sacrifice for their employers, only to fall victim to lay-offs, long working hours and family disruption. For these reasons, millennials tend to have a more holistic approach to their working lives and place high emphasis on work-life balance (Dries, Pepermans, \& De Kerpel, 2008).

\section{Flexible work arrangements and organisational support and trust}

Through the resource theory, Cooper-Thomas, $\mathrm{Xu}$ and Saks (2018) proposed that employee engagement is linked to emotions of warmth and caring. Resources that promote warmth and caring are, therefore, more inclined to improve engagement. Beigi, Shirmohammadi and Stewart (2018) stated that FWAs are portrayed as being supportive in nature. It would be logical that employees who recognise FWAs as 'care' shown by the organisation would lead to higher levels of engagement. The implementation of alternative working arrangements, such as working from home and flexible times, may be representative of an organisation's trust towards their employees, which improves employee morale and motivation (Hill, Ferris, \& Martinson, 2003). This notion is supported by Chen and Fulmer (2017) who state that working from flexible locations may not necessarily improve job satisfaction, but the element of trust motivates employees to work harder in appreciation of the trust instilled in them.

Organisational support theory has become widely researched as it tends to explain employees' relationships with their 
employers. The organisational support theory is made up of three antecedents: fairness, human resource practices and supervisor support (Kurtessis et al., 2017). Building on human resource practices and employee engagement, Bal and De Lange (2014) found that effective human resource management resulted in higher employee engagement.

\section{Performance outcomes associated with employee engagement}

There are various performance outcomes that support employee engagement and the positive effects it has on an organisation's performance. The constructs of employee engagement have been shown to have a positive impact on the employee's work-related experience and state of mind, which leads to increased commitment, productivity and extra role behaviours within the workplace (Schaufeli \& Bakker, 2004).

The positive effects of engaged employees are well researched and recognised in the literature and businesses (Shuck et al., 2017). There is consensus regarding the importance of engaged employees and associated benefits; however, there are no definitive findings around the factors that lead to employee engagement (Bailey et al., 2017). Various antecedents of employee engagement have been identified, including job satisfaction, employee well-being, employer trust, organisational commitment, intention to turnover and organisational support (Shuck et al., 2017). However, further research is required to understand whether an organisation's policy regarding its flexibility can influence the above-listed antecedents of employee engagement.

Figure 1 presents the summary of the relevant literature.

\section{Research design \\ Research approach and strategy}

Given that the research recognised various influences that affect employee engagement, a pragmatic approach that involved being realistic and only focusing on the research questions and objectives was best suited for the study (Saunders \& Lewis, 2012). The research was guided by what was possible and practical. A mono-method qualitative approach is defined as having a singular method of data collection (Collis \& Hussey, 2014). The research used a singular qualitative research method consisting of semistructured interviews with subject matter experts and employees who work within an organisation offering FWAs. Although the data collection was done through a monomethod, it is important to note that there were two aspects of the data collection: firstly, from the organisation's perspective through the interviewing of subject matter experts (Group A), and, secondly, from the employees working for the organisation offering FWAs (Group B).

An inductive research approach is defined as the development of a theory as a result of analysing data that have already been collected (Saunders \& Lewis, 2012). The research undertaken is broad and there are no models designed specifically to test FWAs' impact on employee engagement. Given that the research is explorative in nature, the study looked at assessing current theory and developing the theory by conducting new research.

The research conducted was exploratory in nature, which allowed the researchers to gain new insights, ask new questions and re-examine topics (Saunders \& Lewis, 2012). This method was chosen as there is currently limited and inconclusive research available on the relationship between FWAs and employee engagement. In-depth interviews using a mono-method as the research approach involved the collection of data from a sample group in a semi-structured format (Saunders \& Lewis, 2012).

\section{Research questions}

The research questions were formulated to better understand the influence of FWAs on employee engagement. Furthermore, the study aimed to uncover some of the drawbacks associated

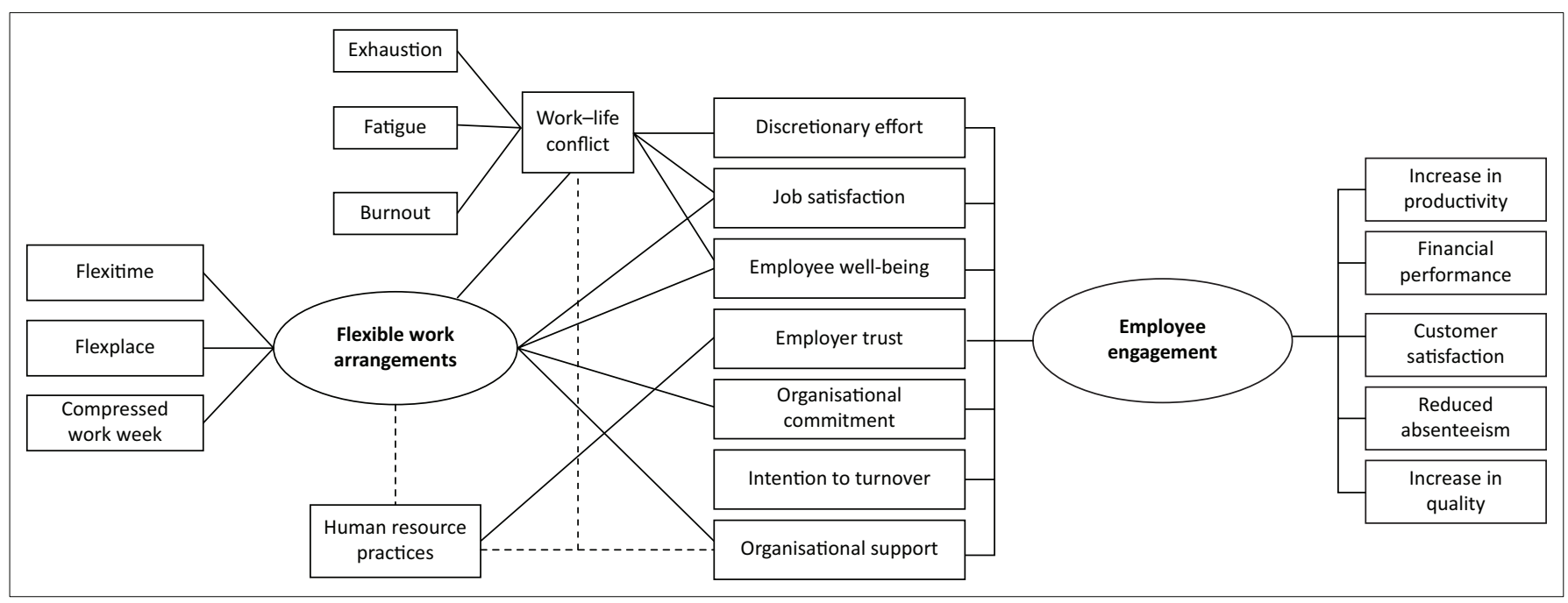

FIGURE 1: Literature review summary. 
with FWAs and gain an understanding of how FWAs can be improved to promote employee engagement.

Research Question 1: why do companies in South Africa choose to implement flexible work arrangements?

The aim of this question was to obtain a broad understanding of an organisation's reasons for implementing FWAs. As this was an exploratory study, the researchers could find themes in addition to the existing literature which have resulted from organisations implementing FWAs.

This research question would assist the researchers to understand what motivates organisations to adopt flexible working practices. The research question would further allow the researchers to gain insights into the benefits associated with the implementation of FWAs.

The interview questions were as follows:

1. Why did your organisation decide to implement FWAs?

2. What flexible work arrangement practices has your organisation implemented and who can use the arrangements?

3. Why those policies? Why those people?

Research Question 2: what perceived employee engagement benefits do organisations recognise from implementing FWAs?

Research Question 2 would explore the relationship that organisations observe between FWAs and employee engagement. Furthermore, it would help to understand the perceived benefits of FWAs, and their association with employee engagement, from the company's perspective. The researchers would also use the data gained from Research Question 2 to understand why the implementation of FWAs is more successful in certain organisations than in others.

The interview questions were as follows:

1. What employee benefits have you observed?

2. What benefits have you observed for the organisation?

Research Question 3: what are employees' lived experiences of FWAs (through an employee engagement lens)?

This question sought to understand how employees feel about FWAs and whether it correlates with the organisation's perceptions (as explored in Research Question 2). It would allow the researchers to understand whether the employees share the same views as the organisation or whether they had conflicting views. The researchers further aimed to understand which aspects of FWAs employees like and which aspects they dislike, determining the potential positive and negative relationships with employee engagement.

The interview questions were as follows:

1. What is your understanding of FWAs? Which FWAs do you use and why do you use them?
2. What are your feelings and thoughts about FWAs? What do you like and dislike about them?

3. Why do you think your organisation offers you FWAs?

4. How important is FWA to you? Would you work for an organisation that doesn't offer you FWAs? Why?

Research Question 4: what are some of the drawbacks of FWA arrangements and how can FWAs be improved to promote employee engagement?

By better understanding the drawbacks and possible improvements to FWAs the researchers aimed to operationalise FWAs and provide practical recommendations to practitioners in an effort to improve employee engagement.

The interview questions were as follows:

1. What are some of the drawbacks of FWAs within your organisation?

2. How can FWAs be improved to promote employee engagement?

\section{Research participants}

The population for this study comprised subject matter experts who have been involved in implementing FWAs or involved in assessing the successes and/or failures of the implemented practice (population A). Interviewees were typically from the human resource department or within human capital and organisational development. The subject matter experts represented their experiences from the organisation's perspective. The second population (population B) was classified as employees working within an organisation that offers FWAs. The employees comprised those who use FWAs and employees who have FWAs at their disposal but do not use them. The employees were selected based on personal networks, referrals and snowball sampling. The researchers ensured that the employees were from various management levels and departments within the organisations in order to reduce bias. Two population groups were used to align with the research questions, which distinguished between the views of the organisations and the views of employees working for the organisations. To broaden the study, the population was selected from various industries, namely, fast foods, financial services, medical insurance, biotechnology, supply chain and manufacturing. To limit the external influences of the perceived value of FWAs, the research was limited to companies operating within the Gauteng province in South Africa.

\section{Sampling method and size}

Purposive sampling was chosen to select the sample participants (Saunders \& Lewis, 2012). This deliberate selection allows the researchers to select the sample that is likely to produce focussed and valuable data to answer the research questions more informatively and economically than probability sampling (Denscombe, 2007). Convenience sampling based on the researchers' personal networks was 
TABLE 1: Industry, function and level of the chosen sample.

\begin{tabular}{lll}
\hline Industry & Function & Level \\
\hline Manufacturing & Organisational effectiveness (FE) & Director \\
& Human resources (FE) & Senior Management \\
& Supply chain (E) & Senior Management \\
& Project management (E) & Middle Management \\
& Research and development (E) & Junior \\
Financial services & General management (FE) & Vice President \\
& Product control (E) & Senior Management \\
& Finance (E) & Junior \\
Medical insurance & Organisational development (FE) & Director \\
& Change management-HR (FE) & Senior Management \\
& Marketing (E) & Middle Management \\
& Data science (E) & Senior Management \\
& Project management (E) & Middle Management \\
& Project management (E) & Junior \\
\hline Fast foods & Human resources (FE) & Director \\
& Business development (E) & Director \\
& Finance (E) & Middle Management \\
& Analytics (E) & Junior \\
\hline Biotechnology & Human resources (FE) & Director \\
& Marketing (E) & Middle Management \\
& Finance (E) & Senior Management \\
& Finance (E) & Junior \\
\hline Human resources (FE) & Director \\
\hline
\end{tabular}

Note: FE, Subject matter expert (representing the organisation); E: employees.

used to obtain interviews with subject matter experts and employees from the selected organisations. A total of 23 participants were interviewed (Table 1).

Eight subject matter experts were interviewed (group A) across the six industries. In some organisations, where the initial respondent felt that one of their colleagues may be able to provide additional insights into the subject, more than one field expert was interviewed. Group A of the sample group represented the views of the organisation and the respondent's expert opinion, and therefore it was important to be pragmatic and consistent in the selection criteria.

In addition to the field expert interviews, employees from the same organisations were interviewed (group B). A sample of two to four employees was interviewed per organisation, which resulted in a total of 15 employees. In order to answer the stated research questions, it was necessary to gain insights from both the organisation's perspective and the lived experiences and views of the employees working within the organisation. As a result, two separate sets of questions were developed to interview respondents from the two groups.

\section{Data collection method}

Given the exploratory nature of the research study, a semistructured interview with subject matter experts using openended questions was used as the research instrument. This provided the researchers the benefit of asking specific questions while simultaneously allowing the interviews to be flexible and to explore common relationships and themes that may emerge in more depth, without influencing the answers participants may give (Saunders \& Lewis, 2012).
Semi-structured interviews were held for a sample of employees. Interviews were all unaided and open-ended. Respondents were encouraged to elaborate on their responses to increase the depth of their responses.

\section{Data collection process}

\section{Interviews with subject matter experts}

The field expert interviews lasted between $25 \mathrm{~min}$ and $1 \mathrm{~h}$ per participant and were guided with timeframes per question. The purpose of semi-structured, open-ended questions was to allow participants to be more intimate while engaging and to acquire more data (Gubrium \& Holstein, 2001).

The second group to be interviewed comprised 15 employees working for the organisations offering FWAs. The data collection process was executed in a manner similar to that of Part A. The employee interviews lasted between 15 and $40 \mathrm{~min}$. The voice recordings were transcribed into word documents and this, together with handwritten notes taken during the interviews, constituted the source of data that were then analysed (Saunders \& Lewis, 2012).

\section{Data recording and analysis}

The researcher used a thematic analysis approach. Thematic analysis is defined as the clustering or categorising of method with the objective of finding patterns in the data (Braun \& Clarke, 2006). The purpose of the thematic analysis is to use the patterns that emerged to answer the research questions. A thematic analysis approach is ideally suited to questions that can be answered through experiences, expert opinions and views of respondents (Saunders \& Lewis, 2012).

Data from the recordings were transcribed and analysed to determine common patterns and trends across all the conducted interviews. Key themes were identified using Atlas.ti version 8 , and data were transformed into a workable format in the form of relationship diagrams. The researchers avoided using a ranking system so that no theme was viewed as more significant than another (Clarke \& Braun, 2016).

\section{Data validity}

With reference to the research strategy, semi-structured interviews were used. The researcher was guided on structure by the literature and allowed for open-ended questions. Because of the nature of this, the data collected will have validity, which is described as the extent to which the questions and measures accurately represent the concept (Zikmund, Babin, Carr, \& Griffin, 2013). The literature review aspect of the research was also expected to identify whether there are any missed themes or gaps that should have emerged in literature, where previous researchers have suggested further research to be carried out. The guidance the literature review provided further demonstrated content validity (Zikmund et al., 2013). 
A recent study conducted by Shuck et al. (2017) revealed three sub-factors of employee engagement (i.e. cognitive, emotional and behavioural) as higher-order factors for employee engagement. The study conferred the employee engagement scale as valid and reliable. The researcher used these constructs found in the literature to ensure that the semi-structured interviews were conducted through an employee engagement lens and to probe respondents where necessary.

\section{Data reliability}

Reliability refers to the data collection and analysis being consistently accurate regardless of source (Saunders \& Lewis, 2012). The researcher aimed to interview five field experts and 15 employees across five different organisations but, owing to sufficient resources, managed to interview six organisations, eight experts and 15 employees.

\section{Ethical consideration}

This article followed all ethical standards for carrying out a research without direct contact with human or animal subjects.

\section{Results}

The results presented are based on the themes that emerged from the qualitative analysis. The themes provide insights into why companies in South Africa decide to implement FWAs, the employee engagement benefit organisations recognise from implementing FWAs, employees' lived experiences of FWA and finally drawbacks and improvements of FWAs for promoting employee engagement.

\section{Results for research question 1: Why do companies in South Africa choose to implement flexible work arrangements?}

Five constructs emerged from analysing the expert interview responses.

\section{Cost saving associated with the implementation of flexible work arrangements}

All eight experts interviewed reported that there was an element of practicality around their decision to implement FWAs. The practicality of what FWAs allow was mentioned throughout the interview process even though this was not the primary motivation for all six organisations. Two experts recognised an additional cost saving, such as utility usage, from having employees work remotely.

Five out of the six organisations had implemented a form of agile working spaces and used 'hot desks' as a means to accommodate more employees than available desks. The implementation of 'hot desks', where employees do not have a permanent workspace, allowed the respective organisations to save on costs associated with office space and, as a result, be able to employ more human capital than what the office could physically accommodate.
Flexible work arrangements perceived as a global trend and a new way of doing business

The majority of the subject matter experts recognised that implementing FWAs was the direction in which business was moving. Five of the experts described the trend as an imperative to remain relevant as an organisation and believed that FWAs are perceived as necessary for an organisation to remain attractive to employees. Four of the experts mentioned how technology has enabled organisations to shift from traditional ways of communication towards modern forms of mobile communication, such as cell phones, laptops, online communication platforms and access to teleconference resources.

The notion of employees being measured on output as opposed to the number of hours worked was a recurring theme shared by all of the experts interviewed. The experts interviewed noted that time spent in the office has become an outdated method by which to measure productivity. The experts shared the views that employee performance should be measured based on their output and performance, further suggesting that hours worked and time in the office is both an intangible and irrelevant measure.

\section{Companies recognising employee needs and how flexible work arrangements accommodate these needs}

The overall consensus from the eight experts was that employee needs have become increasingly important as the concept of employee engagement has gained traction. Experts also commented that in order to have happier and more engaged employees, companies need to take steps to look after their employees from a physical and psychological health perspective. It also became apparent that there was an overlap between responses referring to the catering to employee needs and the attraction and retention of talent.

An evident theme was how organisations have recognised that employees differ in their approach to work and that one method of management cannot accommodate all individuals. Recognising that employees are all individuals with different approaches and needs, the experts suggested that providing flexibility is essential to meet the needs of each employee.

\section{Companies using flexible work arrangements to cater for millennials}

One of the reasons for implementing FWAs was that organisations have recognised that different generations have different preferences and views when it comes to work. Four of the eight experts mentioned that part of their decision to implement FWAs within their organisation was because of the working demands of millennials.

With regard to catering to younger generations, particular emphasis was placed on fostering a culture that encourages agility and innovation. Interviewees echoed these views by stating that organisations that wish to be disruptive and innovative need to promote a work environment and create a culture around flexibility. 


\section{Companies recognising flexible work arrangements as a} necessity to attract and retain talent

The importance of providing FWAs to attract and retain talent was highlighted as significant. Experts felt that FWAs are something employees have started to place significant value on. Therefore, it is important to offer FWAs as a part of an organisation's value proposition as the employees place an increasing value on work-life balance. An important factor stressed by three of the experts was the necessity to remain relevant as an employer and that FWAs allow employees to see the organisation as remaining relevant.

\section{Results for research question 2: What perceived employee engagement benefits do organisations recognise from implementing flexible work arrangements?}

The aim of Research Question 2 was to understand the company's perspective regarding perceived benefits of FWAs associated with employee engagement. The views of the eight experts from the six organisations were analysed to develop the three constructs discussed below.

\section{Higher engagement recognised from implementing flexible work arrangements}

Three of the experts reported that FWAs in their companies had a direct impact on an employee's engagement. The experts also had a level of involvement in the rollout of employee engagement surveys and, although results cannot be directly attributed, they were confident that a relationship existed between offering FWAs and employee engagement results. Within one of the organisations, employee engagement surveys were conducted before and after the implementation of FWAs, and the company representative attributed improvements, in part, to the implementation of FWAs.

Another company expert emphasised the relationship between employee well-being and employee engagement and productivity. Yet another interviewee explained the association between employee happiness and engagement levels, as well as increased output. The view shared by most of the experts was that there is a close relationship between employee happiness, well-being and their level of engagement and output.

\section{Improvement in employees' mental state and well-being}

When experts were asked regarding the benefits of implementing FWAs, one of the major themes that emerged was the improved mental state that employees demonstrated. All of the experts mentioned that they had observed benefits that FWAs have provided to employees.

Happiness was a construct supported by the majority of experts. The experts felt that FWAs allow employees the autonomy to balance their own lives, which in turn makes them happier.

Trust was identified as an important driver of employee morale. The experts interviewed believe that by offering
FWAs to employees, the organisation conveys a message of trust to the employees. This was identified as a key attributor to their morale.

The construct that attracted most of the comments from all experts dealt with employee well-being. Experts felt that there was a clear improvement in the well-being of employees when they were allowed to better balance their work and personal life.

One interviewee reported that FWAs have a significant impact on employees' stress levels and that, by offering FWAs, employees remained more relaxed and less tense in the office environment. Experts found that avoiding traffic had a significant impact on employee stress levels and overall well-being. Their observation was that traffic causes stress and also has a direct impact on productivity because of time wasted during peak hour traffic. Many of the experts also found that FWAs offered employees the option to follow healthier and more active lifestyles. They noted that prior to the implementation of FWAs employees would complain that they were unable to exercise because they did not have enough flexibility in the mornings and evenings.

\section{Improved employee performance}

Four of the company experts contended that employees tended to deliver better results when being measured based on outputs as opposed to time worked in the office. There was also agreement that the quality of work that employees were delivering was of a higher standard. This was attributed to employees not feeling rushed to finish at a certain time but rather being able to balance their working hours and focus on tasks. The notion recognising the fact that employees are also productive under different circumstances was taken into account and experts felt that providing flexibility allowed employees to maximise their productivity based on selfmanagement practices.

There was consensus from all the experts interviewed that having FWAs promotes the culture of being output-focused. Employees were held more accountable for their work when they were measured based on their output. It was an element of 'we don't care how and when you work, as long as the work gets done'. Apart from improved productivity by being more output-focused, experts also felt that the traditional way of managing employees resulted in a lot of unproductive time because employees were measured based on intangible outcomes, such as arrival and departure times.

Another key concept that emerged was that employees were willing to give more to the organisation if they felt that the organisation was giving them something. Experts noted that, by providing FWAs, employees did not work any less but actually worked longer hours because there was no stipulated start and finish time in their day. Experts also noted that there was a form of psychological contract where employees would give discretionary effort back to the organisation as a means of showing appreciation. 


\section{Results for research question 3: What are employees' lived experiences of flexible work arrangements (through an employee engagement lens)?}

Three constructs emerged from analysing the employee interview responses.

\section{Work-life balance}

When employees were asked what their feelings and thoughts were about FWAs, the most common theme that emerged was that they were able to balance their work with their personal life. All 15 employees agreed that FWAs allowed them the flexibility to balance their personal lives with their working arrangements.

Examples provided by the interviewees included the ability to balance work and family conflict, such as fetching their children from school and spending time with them in the evening before they go to sleep. A common arrangement amongst parents was that they would get home earlier to spend time with their children and then work in the evenings after their children have gone to sleep. Another example was related to reduced commute times. This was especially common amongst the employees who worked in densely populated areas, such as Johannesburg and Sandton. Employees felt that avoiding traffic affected their day in terms of their mood and productivity. There were also many employees who mentioned how they manage to become more active with the use of FWAs and many mentioned how they were able to go to gym in the morning or, in cases where FWAs were more intensified, employees would go to the gymnasium during the day and then return to work. These employees felt that exercise during the day stimulated their thinking and increased their productivity.

Contrary to the majority of respondents, a few employees felt that working from home actually decreased their work-life balance because they struggled to differentiate work from personal time. One employee recognised the benefits of working remotely but felt that one of the downsides was that they started working longer hours because they did not know when to stop working. Employees noted that although remote working had no definite start and finish time, the benefits outweighed the negatives, but it was something to become more cognisant about and that self-management strategies needed to be put in place to ensure there was a balance.

\section{Employee morale}

Employees also felt that having FWAs made them enjoy working at the company. The main reason for this was that employees felt less stressed and happier and they also noted the same for their colleagues, which made for a more pleasant office environment.

In addition to the importance of FWAs for employees, many of the respondents referred to the fact that offering FWAs reflected very positively on the company. Most employees mentioned that they would be sceptical about companies that did not offer FWAs as it sends a message that they are rigid in their thinking and lack trust in their employees. Employees mentioned that they would not like to work for an organisation that did not portray flexibility or trust and they felt companies that do not offer FWAs are not forward looking.

\section{Productivity}

Employees found that having FWAs allowed them to be much more productive for numerous reasons. Employees who reported into regional offices also found that having FWAs seemed sensible, as their reporting lines were not in the same geographic regions and in some cases even in different time zones as a result of their direct reports being based in different countries. There was, therefore, a practical aspect associated with FWAs.

Employees felt that all individuals were different and that they were able to use their preferences of working to be most productive. This is because FWAs helped to cater to different individual preferences. Some employees felt that they were more productive at different times of the day, as well as being more productive in different places. One employee mentioned that his job required a great deal of creative thinking and that they are most creative when they are in a comfortable environment, such as their holiday house or working from a coffee shop. The idea of individualism was common amongst the employees interviewed and there was consensus that everybody works differently.

The majority of employees who had the option of working from home felt that they were more productive than when they worked remotely. A common view of employees was that the office can be very distracting. All of the companies used in the study had a form of agile workspaces and the office setups were mostly open. Employees complained that open-plan offices have far too many distractions and can be very noisy, prohibiting productivity.

A shared view of open offices was that it was difficult to focus on single tasks for long periods of time because of distractions and informal meetings taking place. There was also a temptation to socialise in the office. Socialising in the office had perceived advantages, such as interdepartmental communication, but the disadvantage is that employees struggled to buckle down and get work done when deadlines were close.

\section{Results for research question 4: What are some of the drawbacks of flexible work arrangements and how can flexible work arrangements be improved to promote employee engagement?}

This research question used the views of both the experts and the employees within the six chosen companies. The research question was differentiated into two parts. The first part of the 
question referred to the drawbacks associated with FWAs and the second part refers to practical recommendations as to how FWAs can be improved to promote employee engagement.

\section{Part A: Drawbacks of flexible work arrangements}

Abuse of the flexible work arrangements policy: Employees and experts were asked about the question of what some of the negatives associated with FWAs were, to which the majority replied some form of abuse of the policy from their colleagues. Most of the employees mentioned examples of where they have seen people take advantage of the policy and the effects that had on other people within the organisation.

Employees indicated that the FWAs policy resulted in the comparison of who was working more and who was merely taking advantage of the policy. This created internal conflict, especially when work performance was negatively affected, and colleagues were 'dropping the ball'.

Employees felt animosity towards their colleagues who abused the policy because they felt that they gave the policy a bad name and attached an unwanted stigma to it. A concern for the experts was that if they revoked the policy for those abusing it, they would become more disengaged.

\section{Flexible work arrangements resulting in a breakdown of communication within the organisation}

A major drawback that was prevalent in the interviews was that FWAs tended to restrict prompt communication within the organisation. Employees noted that they often had difficulty getting work done when they were reliant on other employees who were using the FWAs. Team members' working times and working spaces were misaligned and this caused challenges when projects required the input of various employees. Many other employees agreed that it was imperative that everyone made a conscious effort to communicate with their team members at all times in order for FWAs to be effective and not disruptive.

One employee felt that FWAs started changing the culture of the organisation in a negative way. The employee felt that the breakdown in communication came from the belief that the organisation was becoming too informal and that professionalism was lost because of this mind shift in the organisation.

\section{Perceived fairness of the flexible work arrangements policy}

A further drawback, expressed by the subject matter experts and the employees of the organisations, was the fairness of the policy. Inconsistency in the use and execution of the policy resulted in employees feeling demotivated and, in some cases, gave rise to resentment towards other employees and the organisation.

The experts felt that the FWAs policy was difficult to manage because much of it comprised informal arrangements made between managers and employees. The result of this was that there was a lack of coherency throughout the organisation. Experts who implemented FWAs also mentioned a challenge in the form of not being able to force the managers to adopt the practice and that it depended on their style of working. By having an incoherent policy, experts found that employees would compare their working arrangements with their peers in other departments and feel disappointed when they came to learn that they had less flexibility in their respective departments.

One of the notable themes that emerged was that FWAs cannot be applicable to the whole organisation because of the impracticality of the policy in certain functions of the business. An example of customer-facing roles, such as the customer services or sales teams, was noted as functions that needed to be available during certain hours for practical purposes. It was found that employees who did not receive these FWAs, did not understand why they were excluded from the policy because the policy was not well defined and did not detail who can or cannot access or use the policy.

\section{Technology readiness}

A drawback noted by the experts and employees was that technology was a prohibiting factor for the successful implementation of FWAs. Many of the employees complained that remote meetings were not very effective. Employees felt that physical presence in meetings was more effective than employees trying to dial in remotely. The majority of employees felt that the standard of technology did not enable fruitful meetings because of poor sound quality.

\section{Part B: Improving flexible work arrangements to promote employee engagement}

Part B of research question 4 aimed to provide practical solutions for the improvement of FWAs, to promote employee engagement. Three constructs were identified as elements that can assist in improving FWAs to promote employee engagement.

\section{Defining and communicating the flexible work arrangements policy}

One of the major challenges, which were mentioned in Part A of research question 4, was that employees felt that the FWAs policy was poorly defined. As a result, there was the perception that the policy is unfair and biased. Experts and employees suggested that the policy would be implemented and perceived better by adopting transparency.

The consensus was that if the policy was better defined there would be no room for misinterpretation, and it would address the concerns around fairness. In five out of the six organisations, the policy had a large element to it which was informal and left to the discretion of line managers who implemented the policy. The researchers found that participants were also not sure what the policy was and who they could approach about using the policy. 


\section{Receiving the buy-in from leadership and management}

The majority of experts and employees felt that FWAs had failed in certain departments because the policy was not embraced by the organisation's leadership team.

One of the experts noted that the policy as a document is just one part of having FWAs in an organisation. This was a common view of both the experts and employees. Flexible work arrangement policies rely on line managers encouraging the use of the policies. Many of the experts also felt that there needed to be a culture shift to adopt this practice and the only way that was attainable was by having the leadership of the company fully support and model the policy.

Resistance to change was a construct that continuously repeated itself when interviewing the experts. Most of the experts were responsible for the implementation of the policy and they noted their biggest challenge was the resistance to adopt the policy by the management team. In one of the companies, it was noted that many of the managers in the organisation were not convinced about the effectiveness of the policy and that made it very difficult for the employees within their teams to comfortably make use of the policy. The expert attributed the lack of buy-in to biases that managers had about the policy. In order to successfully implement FWAs, a trust relationship had to be instilled between managers and their employees.

\section{Improved communication within the organisation}

The majority of experts and employees said that there needs to be improved communication within the organisation so that FWAs do not compromise work being completed and avoid negative effects related to team dynamics and a delay in execution of work. Most of the companies used in the study also noted that they have implemented 'core hours' to promote physical meetings within the office. Core hours are defined as times, generally between 10:00 and 15:00, whereby employees need to be in the office so that they are available for meetings.

Communication between the manager and employee was noted as essential for FWAs to be successful. Employees should inform their managers and their colleagues as to where they are and when they are available. Respondents expressed the importance of an open path of communication between a manager and an employee so that the employee's personal circumstances can be understood and catered for by the manager and as a result the organisation can get the most out of that employee.

\section{Discussion}

\section{Why do companies in South Africa choose to implement flexible work arrangements?}

The data from the interviews suggest that a major incentive for companies to implement FWAs involves the costs associated with office space and utility consumption. Companies noted that office space has become a significant expense as the company expands and noted the impracticalities of having to move offices or redesign office space as they grow. Flexible work arrangements were, therefore, perceived as a solution to extend staff without having to expand office space.

This study investigated what employee's thoughts were regarding why their organisation offers them FWAs. The results indicated that employees who felt that FWAs were granted because 'the company cares' had a more positive attitude towards the organisation when compared to employees who felt the organisation offered FWAs purely as a profit-driven initiative.

Another feature of the results was the observation that companies have recognised that, in order to remain competitive, they need to attract and retain the best talent available (Chabowski \& Mena, 2017). As a result, companies globally have started exploring ways to become more appealing to employees by implementing flexible working arrangements to encourage autonomy and work-life balance. Research has highlighted a positive relationship between organisational support practices and employee performance (Caesens et al., 2016; Kurtessis et al., 2017).

Respondents in the research noted that FWAs have become a popular practice. They also recognised many leading organisations as examples of companies who have high employee engagement and high-performing employees.

A common reference that respondents used as a good example of flexible working and happy employees was 'Google'. Gillett (2016) noted that one of the reasons the global giant 'Google' has such a good reputation and is considered as one of the best companies to work for is because of their holistic view on flexible working. The results also found that organisations believed that output-based management has become a more effective management tool as opposed to traditional methods of judging employee performance. Zeijen et al. (2018) mentioned that organisations have started to be more output focused and have incorporated self-management practices to encourage a more dynamic and decentralised approach to work.

A common motive for organisations to implement a flexible work arrangement policy is to assist employees to better balance their time between work and their personal situations (Chen \& Fulmer, 2017). Kurtessis et al. (2017) argued that organisations cannot afford to ignore employees' needs, as the results could be detrimental to the business. Ignoring the needs of employees can cause significant loss in talent and result in high absenteeism (Kurtessis et al., 2017).

In the interviews, frequent mention was made about the fact that organisations need to cater to the needs of millennials. Literature suggests that employee needs are changing and younger generations entering the working environment are not only motivated by monetary rewards but a balanced life 
has become an expectation (Lyons \& Kuron, 2014). Thompson et al. (2015) stated that younger generations prefer more autonomy and are more inclined to blend work and personal time at their own discretion. Lyons and Kuron (2014) suggested that millennials have become more demanding about having flexibility in their work. Allen et al. (2013) went as far as saying that FWAs were designed for younger generations entering the work environment.

Companies strive to achieve a competitive advantage by attracting and retaining the best talent. A primary reason companies decided to implement FWAs was to remain relevant in the eyes of current and prospective employees. Organisations recognised the fight for talent and mentioned that if you are not moving with the times and giving employees what they want, then they will simply leave. Organisations therefore found FWAs to form a part of their value proposition and all the experts interviewed demonstrated pride in the fact that their organisation offered FWAs. The research found that experts and employees believe that FWAs portray much about a company's culture and values, which is a key factor in retaining and attracting talent.

\section{What perceived employee engagement benefits do organisations recognise from implementing flexible work arrangements?}

When the interviewees were asked whether FWAs could be linked to improved employee engagement, there was a broad agreement that there were engagement benefits to be derived from implementing FWAs.

The views of three of the experts interviewed revealed that there was a direct relationship between FWAs and employee engagement. The experts felt that after implementing FWAs they were able to see the impact in their employee engagement survey results. However, two of the experts noted that there are too many other variables that impact the surveys and an increase in the employee engagement survey scores cannot be directly attributed to FWAs. Part of the justification the researchers used to conduct qualitative research was that it would be difficult to quantify a relationship between the two researched constructs based on various other factors that may have an impact on employee engagement survey results. Timms et al. (2015) agreed that a limitation in quantifying the relationship between FWAs and employee engagement is the external factor which can influence the perceived relationship.

Most of the experts agreed that there is a relationship between FWAs and an employee's engagement. Many of the experts did not necessarily state a direct relationship but they suggested a knock-on effect whereby FWAs impacted antecedents of employee engagement, such as employees' happiness and well-being. The notion of employee happiness and employee well-being having an influence on employee engagement is widely supported in the literature (Agarwal \& Gupta, 2018; Bailey et al., 2017; Shuck et al., 2017; Zhong et al., 2015).
The link between FWAs and employee well-being was also discussed by interviewees. The experts interviewed found various benefits related to overall employees' state of mind and well-being. Benefits observed by the experts included employees' happiness, their attitudes, energy levels, creativity, health, stress levels and sense of empowerment. Employee well-being was a constant point mentioned by all of the experts interviewed. The experts found that FWAs were a successful tool in allowing employees to improve their overall well-being associated with work-life balance and self-management. During the interview process, the experts noted that by offering employees FWAs they saw an improvement in their attitude towards their work. They also noted that they found employees to be less stressed at work. This view is supported in literature by Bakker and Demerouti (2007).

When asked about what employee performance benefits they recognised from implementing FWAs, the majority stated that there was a positive relationship between giving employees the autonomy to carry out their work and their productivity and quality of their work. An increase in performance related to employees' productivity, quality of work and internal and external customer satisfaction was mentioned. The notion that employees were more productive when given the option of having flexibility was based on the opinion that all employees are different, and they are all unique in when and where they are most productive. Experts found that by providing FWAs they could accommodate for different employee working styles. Christian et al. (2011) found that self-management resulted in higher engagement and discretionary effort. Literature also suggests that engagement increases with perceived autonomy (Llorens, Schaufeli, Bakker, \& Salanova, 2007).

The study found that there is an increase in productivity for the majority of employees; however, the experts did point out that there are employees who abuse the policy, and this naturally results in a decrease in employee performance. Overall, the study found that productivity increased when employees used FWAs. Gajendran and Harrison (2007) found that FWAs are positively associated with increased productivity and employee attitudes.

\section{What are employees' lived experiences of flexible work arrangements?}

The most prevalent theme emerging from the interviews with employees was that they experienced a better work-life balance as a result of FWAs. Employees gave various examples of how they were better able to balance their worklife by having FWAs; these included less time spent on commutation, more family time and more time to do personal activities such as going to the gym and running errands.

Non-monetary initiatives by employers, such as FWAs, are becoming increasingly popular as they have been recognised as successful practices to help employees better balance their lives (Zheng et al., 2015). Employers mentioned that FWAs 
need to work in conjunction with other policies that help employees maintain a work-life balance, such as providing fitness facilities and health days.

Many of the employees interviewed said that FWAs have allowed them to decrease their commute times, which was mentioned as a source of stress and lower productivity because of time wasted in traffic. This view is supported by the literature which states that commute times are found to result in stress (Zhou et al., 2017) and absenteeism (Van Ommeren \& Gutierrez-i-Puigarnau, 2011).

Some researchers have argued that FWAs can negatively impact work-life balance because employees are unable to differentiate between work and personal time, especially when working from home (Hill et al., 2003) and that working from home can increase stress (Schmidt \& Neubach, 2007). Only two employees out of the 15 interviewed felt that, by working from home, work-family conflict increased because they were not able to distance themselves from their work as there was technically no start and finish time. The results revealed that employees suggested that working from home requires discipline not only to perform their work but to know when to stop working.

In addition to the positive impact on work-life balance, the study also found that morale also improved as a result of FWAs: employees felt trusted and respected by their organisations. The majority of employees also reported that by offering FWAs their organisation was practising its values. Employees felt empowered when they were granted the autonomy to perform their work.

One of the main facts that emerged from the data was the construct of trust. Employees explained how they tend to feel more appreciated and motivated when their employer shows them trust through their FWAs and, conversely, employees felt that being micromanaged showed a lack of trust which demotivated and disengaged them. Chen and Fulmer (2017) found that FWAs promoted trust within employees, which results in more motivated and harder working employees. Hill et al. (2003) also suggested that by showing employees trust, employee morale and motivation improve. Employees also felt that they were more productive as a result of FWAs. The reasons for increased productivity were related to less distraction when working from home, being able to work at times that they are most productive and having less workfamily conflict that allowed them to be more focused on their work.

Another key concept that the results showed was that employees were more willing to put in extra effort in exchange for the flexibility shown by the organisation. This is referred to as discretionary effort in the literature, a primary output of employee engagement (Agarwal \& Gupta, 2018; Bailey et al., 2017; Brunetto et al., 2012; Rich et al., 2010; Saks, 2006; Shuck et al., 2017; Zhong et al., 2015).

\section{Drawbacks associated with flexible work arrangements}

One of the potential problems associated with offering FWAs to employees is employees taking advantage of the policy and misusing the flexibility being offered. Abuse of the policy included employees starting late and leaving early, employees claiming to work from home when undertaking personal activities and employees not achieving their work assignments as a result of not spending the necessary time on work activities.

The abuse of the policy seemed to be the exception rather than the norm. The experts interviewed found it difficult to manage employees who were abusing the policy and suggested that revoking the flexibility for all would not be fair and taking it away from the individual would result in resentment and disengagement. A constant fact that was presented was that if the policy was better defined there would be no grey areas whereby employees could take advantage of the flexible arrangements provided.

A concern raised by some employees was that communication had suffered as a consequence of colleagues having FWAs. Some concerns noted by employees were that their colleagues were unavailable for meetings and it was difficult to meet deadlines when relying on colleagues who were availing FWAs. The results also showed that FWAs often had a negative impact on the team dynamic, especially where communication was poor. This was often owing to the use of unreliable methods of technology to compensate for not being physically present in the office. Timms et al. (2015) suggested that organisations implementing flexible working strategies need to ensure effective two-way communication to avoid a breakdown in communication within organisations.

Concerns were raised by the interviewees related to the perceived fairness of FWAs. Flexible work arrangements were at times implemented at the manager's discretion and this could result in inconsistency across different managers and departments. The result of the inconsistency was that employees started comparing themselves to one another and questioning why some employees had more flexibility than others. The notion of favouritism was a concern raised by employees and it could result in feelings of injustice and resentment, ultimately causing employees to become disengaged with their work. Perceived fairness was also largely impacted by the company's culture and resistance to change. A number of employees noted that the culture of the organisation and perceptions of many managers did not support the notion of FWAs. Hegtvedt, Clay-Warner and Ferrigno (2002) support the conception that a perceived lack of fairness around FWAs results in resentment amongst employees. The study showed that employees who did not receive FWAs were resentful to those who had FWAs and as a result were less engaged.

A further potential drawback of FWAs was related to technology. Inadequate technology readiness was closely 
associated with the breakdowns in communication. The study revealed that poor technology capabilities as a result of poor Internet connectivity and inadequate telecommunications application software resulted in ineffective remote communication. It also showed that employees in more technically demanding roles that required the use of advanced software were unable to work remotely when connectivity to the local network was unavailable. Experts and managers also noted that technology was a key enabler of successfully implementing FWAs. A significant investment into enablers such as laptops and mobile data connectivity was imperative to successfully implement FWAs. This finding is not prominent in the literature with the assumption that more developed countries, such as the United States, may be more technologically advanced.

\section{How flexible work arrangements can be improved to promote employee engagement?}

Findings from the research suggest that companies that had poorly defined FWAs were not successful in implementing FWAs and as a result were not recognising its benefits. It also found that the arrangements were generally at the discretion of managers. A poorly defined policy also had an effect on the management process of FWAs and the fairness of how the policy could be used and who was allowed to use the policy.

To remove the bias associated with FWAs, it was found that the policy needed to be more openly discussed. The study found that employees who had open communication about their personal circumstances with their managers and received well-defined FWAs showed much higher levels of engagement than those employees who did not have this same level of openness and understanding with their managers.

The study also found that it was imperative for managers to have a good understanding of the FWAs policy and understand why the organisation has the policy. An organisation needs to foster a culture that encourages acceptance of the policy. Unless the policy is embraced, inconsistencies and biases will remain, which will result in poor implementation and adoption by employees. Literature has supported the notion that embracing the policy through an enabling culture is important (Timms et al., 2015). Literature has further supported the study's findings by emphasising the importance of a two-way communication amongst managers and employees (Timms et al., 2015).

Respondents emphasised the importance of management buying into the notion of FWAs. The support from the leadership team was noted as essential for FWAs to effectively drive employee engagement. The study found that FWAs were often nothing more than a policy and that the lack of acceptance by management meant that the policy was more 'lip service' than actually becoming a part of the organisation's culture and way of working.
The study also found that having FWAs in isolation was not an effective strategy to promote employee engagement. The study suggests that organisations need to incorporate other supportive practices and foster an agile working culture to successfully improve employee engagement.

Respondents noted that for companies to fully achieve the positive effects of FWAs, improved communication was necessary. The study found that FWAs are a relatively new arrangement and employees are often poorly equipped to communicate effectively without being physically present in the office. The study suggests that communication tools should be enhanced within organisations offering FWAs. These tools include better use of information sharing platforms, which allow team members to be aware of one another's working arrangements, as well as the overall improvement in etiquette related to informing one another about deadlines and attendance of meetings.

The study also found that FWAs' success was highly dependent on line managers successfully managing the policy. The study found that the onus was on the managers to make FWAs a success. Without managers having good relationships with their employees, knowing what FWAs they require and creating a psychological contract with their employees around the appropriate use of FWAs, the practice would be a failure.

\section{Conclusion}

The research set out to explore the influence of FWAs on employee engagement. The study can be summarised into three main areas. The first area deals with the necessity for organisations to implement FWAs. The researchers found five main reasons for why organisations in South Africa have started implementing FWAs. The reasons can be summarised into an overarching construct: that the business landscape is changing, and employee needs have become an important element for businesses to remain competitive (Chabowski \& Mena, 2017). The second area of this study examined the employee engagement benefits to be gained from implementing FWAs. The benefits associated with FWAs can be summarised as work arrangements that impact positively overall employee well-being, a precondition for employee engagement (Agarwal \& Gupta, 2018; Bailey et al., 2017; Brunetto et al., 2017; Zhong et al., 2015). Furthermore, FWAs can promote employee productivity, which is a recognised outcome of employee engagement (Kahn \& Heaphy, 2014). Lastly, this study identified some of the drawbacks of FWAs which included breakdowns in communication and a lack of fairness, which can result in various negative outcomes.

A primary objective of the research was to provide practical recommendations to practitioners by understanding some of the drawbacks of FWAs and to identify ways of improving FWAs in order to promote employee engagement. 
Through the conduction of a gap analysis, the research was able to identify drawbacks of FWAs that were not recognised in the literature. Most of the literature was based on quantitative studies that sought to find whether a relationship exists between FWAs and constructs of employee engagement. These did not tend towards prioritising the drawbacks and seeking improvements for the practical implementation of FWAs. The study found that poor management of FWAs can have important negative effects on the business, including breakdown in communication and abuse of the policy by employees. The perceived fairness of the policy was found to be crucial in the successful implementation of the policy. Literature advocates fairness as a prerequisite for employee well-being and engagement (Caesens et al., 2016). It was further found that the readiness of technology as an enabler to remote working was overlooked by organisations implementing the practice.

\section{A proposed framework}

The aim of this study was to understand the influence of FWAs on employee engagement but, more so, to understand why the relationship exists, what causes the relationship and how it can be improved to promote employee engagement.

The framework below has been created as a summary and conceptualisation of the findings from the research (see Figure 2).

The framework has three key criteria for the successful implementation and management of FWAs. The first criterion is to define and communicate the policy. This research found that poorly defined policies within organisations offering FWAs resulted in a distorted perception of fairness. Furthermore, employees showed disengagement when they did not have access to the policy without understanding the reason why. The research also proposes that a poorly defined policy was open to misinterpretation which resulted in some employees abusing the policy. By defining the policy well, employees also recognised that the organisation cares about them and supports them, which was found to be a key driver of employee engagement. Core working hours should also be clearly communicated so that there is no misunderstanding around start and finish times and no breakdown in team meetings.

The second criterion for successfully implementing FWAs is to receive the buy-in from management. One of the biggest prohibiting factors found, which hampers employee engagement, was the lack of buy-in from management into the policy. It is essential for companies to fully embrace the policy and further have the company's leadership team model the policy. Biases need to be removed from the policy and this could be done by training managers about the policy and how to manage the policy. For FWAs to be truly effective, the change needs to be embraced and biases need to be removed so that employees do not end up with feelings of guilt, resentment and reluctance to use the policy. These are all detrimental to employee engagement.

The third criterion for implementing and managing FWAs involves creating an enabling environment. Based on the evidence found in the research, it is strongly suggested that an enabling culture is needed for FWAs to effectively drive employee engagement. The environment should include practical factors. These include ensuring the necessary technology is available for employees to work remotely, ensuring the availability of communication platforms and, lastly, ensuring supporting practices are in place to compliment FWAs. These supporting practices include agile workspaces, health promoting initiatives and a supportive working environment.

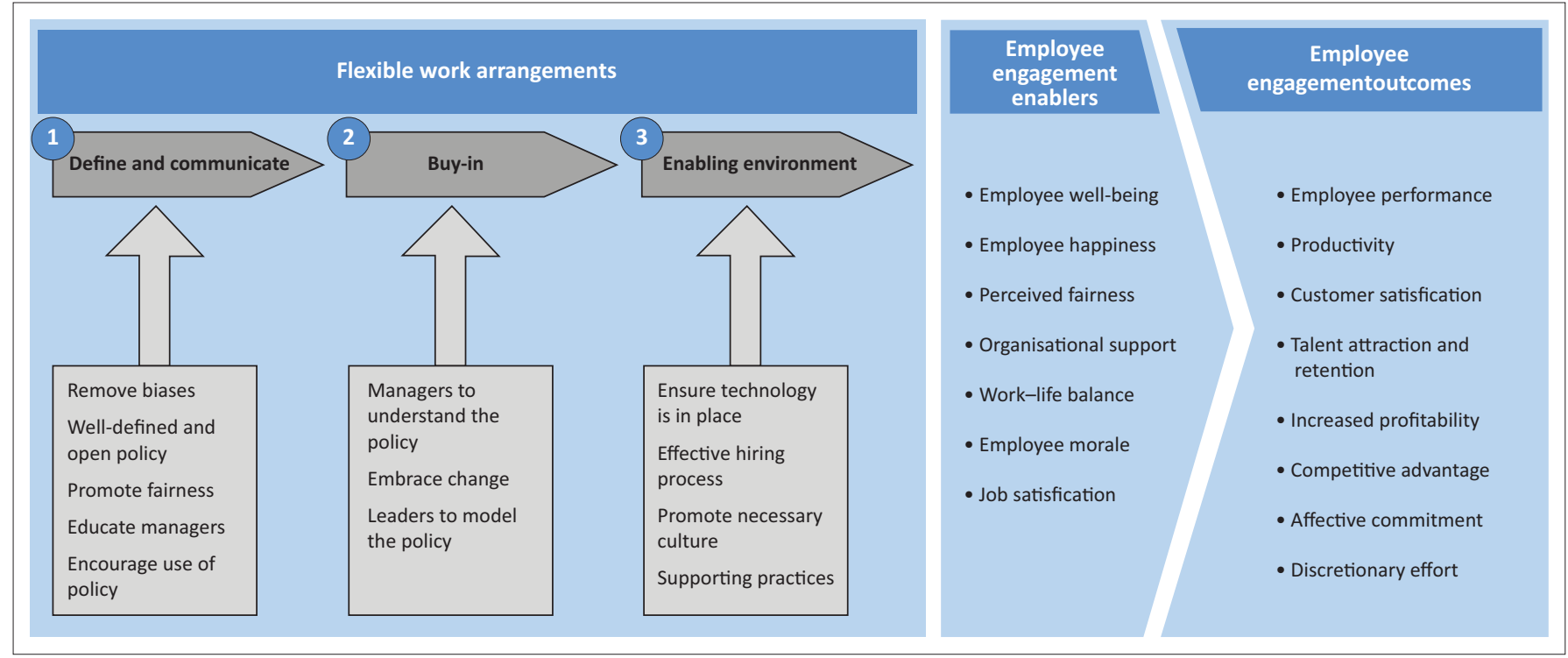

FIGURE 2: Flexible work arrangements framework. 
The three criteria mentioned in the framework were found to positively affect various enablers of employee engagement, such as employee well-being, employees' perception of fairness and support by the organisation, employees' work-life balance, happiness and morale and their levels of job satisfaction. The successful management of FWAs was also found to have a direct impact on employee engagement outcomes, such as productivity, talent attraction and retention, discretionary effort and organisational commitment.

\section{Practical implications}

This research has proposed practical ways in which practitioners can successfully manage and implement FWAs to promote employee engagement. The research has recognised that FWAs have an influence on various constructs of employee engagement, which has become a necessary driver for businesses to gain a competitive advantage and enhance performance outcomes. The research has also uncovered gaps in the literature, which have been operationalised in the form of a framework to guide practitioners in successfully improving employee engagement within their organisations.

The implications for business can be highlighted as follows:

- Implementing FWAs has become a necessity for organisations to save costs, cater for employees' needs, attract and retain talent, and cater to variations in employees' generational demands.

- Flexible work arrangements are successful tools to promote employee well-being, which is necessary for employee engagement to proceed.

- Employees recognise organisational support and autonomy as a sign of trust and respect and are more likely to display discretionary effort and commitment to the organisation.

- Organisations need to recognise that not all employees have the same response to traditional working environments and, based on this notion, companies need to use FWAs to cater to different working styles in order for employees to produce their best results.

- Perceived fairness by employees is a major element when implementing policies.

- Organisations need to recognise that FWAs in isolation are not enough to improve employee well-being and that a specific culture is necessary to recognise the effects of employee engagement.

- Limitations to implement FWAs can have negative outcomes. It is necessary for organisations to first ensure that structural enablers, such as technology, are in place.

- The buy-in into the policy is an imperative for the implementation of FWAs. Implementing FWAs with poor buy-in from management results in resentment and disengagement of employees. Furthermore, the policy needs to be modelled by leadership within the business to remove biases and negativity around the policy.

\section{Limitations}

The limitations of the study can be noted as follows:

- The relatively small sample size limits the ability to generalise the findings to other contexts.

- The study only used organisations that offer FWAs, which may have encouraged bias in the study.

- The research was limited to multinational organisations across six different industries.

- The majority of employees interviewed were professionals with tangible outcomes. The results may have shown higher levels of abuse and difficulty in implementing FWAs with employees whose work is less tangibly measured.

- Four out of the eight subject matter experts interviewed were responsible for the implementation of FWAs and could, therefore, be seen as being less objective.

- Organisations used in the study had the reputation for already having high employee engagement and the effects of FWAs could be somewhat distorted by other enabling cultural elements of employee engagement.

\section{Suggestions for future research}

- Throughout the data-gathering process, the researchers noted potential themes emerging which were outside of the scope of research. These are, therefore, suggested as potential future research.

- There is little empirical evidence around different generational views of FWAs. This qualitative study suggests that millennials value FWAs significantly more than older generations; however, further research is required in this regard.

- The researchers found that women were perceived to value FWAs more than men. Further research around gender preferences to FWAs will help better understand the value that different genders place on work-family conflict and FWAs.

- The research was limited to organisations offering FWAs and more focused on the positive effects of FWAs. Future research may reveal that there are many more drawbacks associated with FWAs and it may be of value to study companies that do not have FWAs and understand why they have decided not to implement the practice.

- The research found that open plan offices tended to disrupt employees. Further research is required to understand the effects that open plan offices have on employee productivity and engagement.

The literature has found varying results around the influence of FWAs on employee engagement. This study has concluded that FWAs have a positive influence on various constructs of employee engagement, with the most prevalent finding being that FWAs promote employee well-being, which was observed as a key enabler of employee engagement. The research further recognised various gaps in the literature with regard to the drawbacks of FWAs and further managed 
to create a framework which highlights the necessary criteria and climate needed to implement and manage FWAs to promote employee engagement.

The research has, therefore, not only contributed to the literature by supporting the notion of FWAs influencing employee engagement, but also intends to contribute to the practice of management through the use of the 'Flexible Work Arrangements' framework by managers and leaders who are trying to improve employee engagement through the advancement of flexible working practices.

\section{Acknowledgements \\ Competing interests}

The authors have declared that no competing interests exist.

\section{Authors' contributions}

M.W. undertook the research under the supervision of Prof. K.B. Hofmeyr.

\section{Funding information}

This research received no specific grant from any funding agency in the public, commercial or not-for-profit sectors.

\section{Data availability statement}

Data sharing is not applicable to this article as no new data were created or analysed in this study.

\section{Disclaimer}

The views and opinions expressed in this article are those of the authors and do not necessarily reflect the official policy or position of any affiliated agency of the authors.

\section{References}

Agarwal, U., \& Gupta, V. (2018). Relationships between job characteristics, work engagement, conscientiousness and managers' turnover intentions. Personnel Review, 47(2), 353-377. https://doi.org/10.1108/pr-09-2016-0229

Allen, T., Johnson, R., Kiburz, K., \& Shockley, K. (2013). Work-family conflict and flexible work arrangements: Deconstructing flexibility. Personnel Psychology, 66(2), 345-376. https://doi.org/10.1111/peps.12012

Bailey, C., Madden, A., Alfes, K., \& Fletcher, L. (2017). The meaning, antecedents and outcomes of employee engagement: A narrative synthesis. International Journal of Management Reviews, 19(1), 31-53. https://doi.org/10.1111/ijmr.12077

Bakker, A., \& Demerouti, E. (2007). The job demands-resources model: State of the art. Journal of Managerial Psychology, 22(3), 309-328. https://doi.org/ 10.1108/02683940710733115

Bal, P., \& De Lange, A. (2014). From flexibility human resource management to employee engagement and perceived job performance across the lifespan: A multi sample study. Journal of Occupational and Organizational Psychology, 88(1), 126-154. https://doi.org/10.1111/joop.12082

Beigi, M., Shirmohammadi, M., \& Stewart, J. (2018). Flexible work arrangements and work-family conflict: A meta synthesis of qualitative studies among academics. Human Resource Development Review, 17(3), 314-336. https://doi. org/10.1177/1534484318787628

Braun, V., \& Clarke, V. (2006). Using thematic analysis in psychology. Qualitative Research in Psychology, 3(2), 77-101. https://doi.org/10.1191/1478088706qp063oa

Brunetto, Y., Teo, S., Shacklock, K., \& Farr-Wharton, R. (2012). Emotional intelligence, job satisfaction, well-being and engagement: Explaining organisational commitment and turnover intentions in policing. Human Resource Management Journal, 22(4), 428-441. https://doi.org/10.1111/j.1748-8583.2012.00198.x
Burke, R., \& Ng, E. (2006). The changing nature of work and organizations: Implications for human resource management. Human Resource Management Review, 16(2), 86-94. https://doi.org/10.1016/j.hrmr.2006.03.006

Caesens, G., Marique, G., Hanin, D., \& Stinglhamber, F. (2016). The relationship between perceived organizational support and proactive behaviour directed towards the organization. European Journal of Work and Organizational Psychology, 25(3), 398-411. https://doi.org/10.1080/1359432x.2015.1092960

Casper, W., \& Harris, C. (2008). Work-life benefits and organizational attachment: Selfinterest utility and signaling theory models. Journal of Vocational Behavior, 72(1), 95-109. https://doi.org/10.1016/j.jvb.2007.10.015

Chabowski, B., \& Mena, J. (2017). A review of global competitiveness research: Past advances and future directions. Journal of International Marketing, 25(4), 1-24. https://doi.org/10.1509/jim.16.0053

Chen, Y., \& Fulmer, I. (2017). Fine-tuning what we know about employees' experience with flexible work arrangements and their job attitudes. Human Resource Management, 57(1), 381-395. https://doi.org/10.1002/hrm.21849

Christian, M., Garza, A., \& Slaughter, J. (2011). Work engagement: A quantitative review and test of its relations with task and contextual performance. Personnel Psychology, 64(1), 89-136. https://doi.org/10.1111/j.1744-6570.2010.01203.x

Clarke, V., \& Braun, V. (2016). Thematic analysis. The Journal of Positive Psychology, 12(3), 297-298. https://doi.org/10.1080/17439760.2016.1262613

Collis, J., \& Hussey, R. (2014). Business research: A practical guide for undergraduate and postgraduate students (4th edn., p. 54). Basingstoke: Palgrave Macmillan.

Cooper-Thomas, H., Xu, J., \& M. Saks, A. (2018). The differential value of resources in predicting employee engagement. Journal of Managerial Psychology, 33(4/5), 326-344. https://doi.org/10.1108/jmp-12-2017-0449

Denscombe, M. (2007). The good research guide for small scale research projects (3rd edn.). Berkshire: Open University Press.

Dries, N., Pepermans, R., \& De Kerpel, E. (2008). Exploring four generations' beliefs about career. Journal of Managerial Psychology, 23(8), 907-928. https://doi. org/10.1108/02683940810904394

Gajendran, R., \& Harrison, D. (2007). The good, the bad, and the unknown about telecommuting: Meta-analysis of psychological mediators and individual consequences. Journal of Applied Psychology, 92(6), 1524-1541. https://doi. org/10.1037/0021-9010.92.6.1524

Gallup, I. (2016). Gallup Q12 ${ }^{\circledR}$ meta-analysis report. Retrieved from http://news. gallup.com/reports/191489/q12-meta-analysis-report-2016.aspx

Gillett, R. (2016). 5 reasons Google is the best place to work in America and no other company can touch it. Retrieved from https://www.businessinsider.com/googleisthe-best-company-to-work-for-in-america-2016-4?IR=T

Gubrium, J., \& Holstein, J. (2001). Handbook of interview research: Context and method. Thousand Oaks, CA: Sage.

Hammer, L., Neal, M., Newsom, J., Brockwood, K., \& Colton, C. (2005). A longitudinal study of the effects of dual-earner couples' utilization of family-friendly workplace supports on work and family outcomes. Journal of Applied Psychology, 90(4), 799-810. https://doi.org/10.1037/0021-9010.90.4.799

Hegtvedt, K., Clay-Warner, J., \& Ferrigno, E. (2002). Reactions to injustice: Factors affecting workers' resentment toward family-friendly policies. Social Psychology Quarterly, 65(4), 386. https://doi.org/10.2307/3090109

Hill, E., Ferris, M., \& Martinson, V. (2003). Does it matter where you work? A comparison of how three work venues (traditional office, virtual office, and home office) influence aspects of work and personal/family life. Journal of Vocational Behavior, 63(2), 220-241. https://doi.org/10.1016/s00018791(03)00042-3

IOL Business Report. (2017). Consequences of flexible working hours. Retrieved n.d. from https://www.iol.co.za/business-report/careers/consequences-of-flexibleworking-hours-9411450

Kahn, W. (1990). Psychological conditions of personal engagement and disengagement at work. Academy of Management Journal, 33(4), 692-724. https://doi.org/ $10.5465 / 256287$

Kahn, W., \& Heaphy, E. (2014). Relational contexts of personal engagement at work. In E. Soane, A. Shantz, K. Alfes, R. Delbridge \& C. Truss (Eds.), Employee engagement in theory and practice (pp. 15-17). New York, NY: Routledge.

Kurtessis, J., Eisenberger, R., Ford, M., Buffardi, L., Stewart, K., \& Adis, C. (2017) Perceived organizational support: A meta-analytic evaluation of organizational support theory. Journal of Management, 43(6), 1854-1884. https://doi. org/10.1177/0149206315575554

Leslie, L., Manchester, C., Park, T., \& Mehng, S. (2012). Flexible work practices: A source of career premiums or penalties? Academy of Management Journal, 55(6), 1407-1428. https://doi.org/10.5465/amj.2010.0651

Llorens, S., Schaufeli, W., Bakker, A., \& Salanova, M. (2007). Does a positive gain spiral of resources, efficacy beliefs and engagement exist? Computers in Human Behavior, 23(1), 825-841. https://doi.org/10.1016/j.chb.2004.11.012

Lyons, S., \& Kuron, L. (2014). Generational differences in the workplace: A review of the evidence and directions for future research. Journal of Organizational Behavior, 35(Suppl 1), S139-S157. https://doi.org/10.1002/job.1913

Michel, J., Kotrba, L., Mitchelson, J., Clark, M., \& Baltes, B. (2011). Antecedents of work-family conflict: A meta-analytic review. Journal of Organizational Behavior, 32(5), 689-725. https://doi.org/10.1002/job.695

Rich, B., Lepine, J., \& Crawford, E. (2010). Job engagement: Antecedents and effects on job performance. Academy of Management Journal, 53(3), 617-635. https:// doi.org/10.5465/amj.2010.51468988 
Saks, A. (2006). Antecedents and consequences of employee engagement Journal of Managerial Psychology, 21(7), 600-619. https://doi.org/10.1108/ 02683940610690169

Saunders, M., \& Lewis, P. (2012). Doing research in business and management: An essential guide to planning your project. Harlow: Pearson.

Schaufeli, W., \& Bakker, A. (2004). Job demands, job resources, and their relationship with burnout and engagement: A multi-sample study. Journal of Organizational Behavior, 25(3), 293-315. https://doi.org/10.1002/job.248

Schmidt, K., \& Neubach, B. (2007). Self-control demands: A source of stress at work. International Journal of Stress Management, 14(4), 398-416. https://doi. org/10.1037/10725245.14.4.398

Shuck, B., Adelson, J., \& Reio, T. (2017). The employee engagement scale: Initia evidence for construct validity and implications for theory and practice. Human Resource Management, 56(6), 953-977. https://doi.org/10.1002/hrm.21811

Skinner, N., \& Chapman, J. (2013). Work-life balance and family friendly policies. Evidence Base, 2013(4), 1-17. https://doi.org/10.21307/eb-2013-002

Sweet, S., Pitt-Catsouphes, M., \& Boone James, J. (2016). Successes in changing flexible work arrangement use. Work and Occupations, 43(1), 75-109. https:// doi.org/10.1177/0730888415595094

Thompson, R., Payne, S., \& Taylor, A. (2015). Applicant attraction to flexible work arrangements: Separating the influence of flextime and flexplace. Journal of Occupational and Organizational Psychology, 88(4), 726-749. https://doi. org/10.1111/joop.12095

Timms, C., Brough, P., O’Driscoll, M., Kalliath, T., Siu, O., Sit, C., \& Lo, D. (2015). Flexible work arrangements, work engagement, turnover intentions and psychological health. Asia Pacific Journal of Human Resources, 53(1), 83-103. https://doi. org/10.1111/1744-7941.12030

TomTom Traffic Index. (2016). Retrieved n.d. from https://corporate.tomtom.com/ static-files/5289c5aa-310c-4965-a4c0-516760a8a6fd
Towers Watson. (2017). Employee insights for a better employee experience: A panel discussion of companies leading the curve. Retrieved from https://www.towerswatson.com/en-ZA/Insights/Newsletters/Global/ SustainablyEngaged/2017/employee-insights-for-a-better-employee-experience

Van Ommeren, J., \& Gutiérrez-i-Puigarnau, E. (2011). Are workers with a long commute less productive? An empirical analysis of absenteeism. Regional Science and Urban Economics, 41(1), 1-8. https://doi.org/10.1016/j.regsciurbeco.2010. 07.005

World at Work. (2015). Trends in workplace flexibility. Scottsdale, AZ. Retrieved from https://www.worldatwork.org/dA/10dc98de55/Trends\%20in \% 20 Workplace\%20Flexibility\%20-\%202015.pdf

Zeijen, M., Peeters, M., \& Hakanen, J. (2018). Workaholism versus work engagement and job crafting: What is the role of self-management strategies? Human Resource Management Journal, 28(2), 357-373. https://doi.org/10.1111/17488583.12187

Zheng, C., Kashi, K., Fan, D., Molineux, J., \& Ee, M. (2015). Impact of individual coping strategies and organisational work-life balance programmes on Australian employee well-being. The International Journal of Human Resource Management 27(5), 501-526. https://doi.org/10.1080/09585192.2015.1020447

Zhong, L., Wayne, S., \& Liden, R. (2015). Job engagement, perceived organizational support, high-performance human resource practices, and cultural value orientations: A cross-level investigation. Journal of Organizational Behavior, 37(6), 823-844. https://doi.org/10.1002/job.2076

Zhou, L., Wang, M., Chang, C., Liu, S., Zhan, Y., \& Shi, J. (2017). Commuting stress process and self-regulation at work: Moderating roles of daily task significance, family interference with work, and commuting means efficacy. Personnel Psychology, 70(4), 891-922. https://doi.org/10.1111/peps.12219

Zikmund, W.G., Babin, B.J., Carr, J.C., \& Griffin, M. (2013). Business research methods. Mason, $\mathrm{OH}$ : Cengage. 